\title{
Term Structure and Cyclicity of Value-at-Risk: Consequences for the Solvency Capital Requirement
}

\author{
FRÉDÉRIQUE BEC \\ CHRISTIAN GOLLIER
}

CESIFo WORKING PAPER NO. 2596

CATEGORY 11: INDUSTRIAL ORGANISATION

MARCH 2009

An electronic version of the paper may be downloaded

- from the SSRN website:

- from the RePEc website:

- from the CESifo website:

www.SSRN.com

www.RePEc.org

www.CESifo-group.org/wp 


\title{
Term Structure and Cyclicity of Value-at-Risk: Consequences for the Solvency Capital Requirement
}

\begin{abstract}
This paper explores empirically the link between French equities returns Value-at-Risk (VaR) and the state of financial markets cycle. The econometric analysis is based on a simple vector autoregression setup. Using quarterly data from 1970Q4 to 2008Q3, it turns out that the kyear $\mathrm{VaR}$ of French equities is strongly dependent on the cycle phase: the expected losses as measured by the VaR are twice smaller in recession times than expansion periods. These results strongly suggest that the European rules regarding the solvency capital requirements for insurance companies should adapt to the state of the financial market's cycle. To this end, we propose a cycle-dependent measure of the Solvency Capital Requirement.

JEL Code: G11.
\end{abstract}

Keywords: expected equities returns, Value at Risk, investment horizon, vector autoregression.

Frédérique Bec

Théma - University of Cergy-Pontoise

33, boulevard du Port

95011 Cergy-Pontoise Cedex

France

bec@ensae.fr

\author{
Christian Gollier \\ Toulouse School of Economics \\ University of Toulouse I \\ Place Anatole France \\ 31042 Toulouse cedex \\ France \\ gollier@cict.fr
}

Paris, 10th February 2009

This version of the paper has benefited from numerous discussions with Severine Marion. All remaining errors are ours. The authors gratefully acknowledge financial support by the Fédération Française des Sociétés d'Assurance. 


\section{Introduction}

A growing empirical literature points to predictability in equities returns, at least to some extent (see e.g. Campbell [1991], Campbell [1996], Barberis [2000], or Campbell and Viceira [2002] for U.S. data and Bec and Gollier [2007] for french data). This in turn implies the existence of an horizon effect in the risk of equities returns. More precisely, U.S. and French equities risk are found to be mean reverting, in the sense that the risk associated with long holding periods is lesser than the one associated with short holding horizons as e.g. the widely scrutinized one-year horizon.

Our claim, in this paper, is that the equities returns dynamics, and hence their Valueat-Risk (VaR hereafter) may be influenced by the state of the financial market cycle. The idea is that the expected $k$-period returns should not be the same depending on whether the financial market is near a peak or near a trough. This potential influence is explored empirically by modelling the joint dynamics of excess return of equities and an indicator of the financial market cycle from a vector autoregression model. Actually, in the recent empirical literature devoted to asset returns predictability, the vector autoregressive dynamics is often retained. The choice of this representation is basically motivated by two reasons. The first one is that this framework allows for straightforward computation of the conditional first and second-order moments matrices, namely the conditional mean and variance-covariance matrices. Hence, two crucial variables for dynamic portfolio allocation optimization obtain easily - the time- $t$ conditional expectation (forecast) and conditional variance (risk measure) for asset returns at horizon $t+h$. The second reason is that under the assumption that asset returns are well described by such a vector autoregression model, it is possible to obtain approximate solutions to some multiperiod portfolio choice model as e.g. the one developed in Campbell, Chan and Viceira [2003]. ${ }^{1}$

Some recent papers (Adrian and Shin (2007, 2008), Plantin, Sapra and Shin [2008], Rochet [2008]) suggest that Basel II and the International Accounting Standards norm

\footnotetext{
${ }^{1}$ In their model, the investor is infinitely-lived with Epstein-Zin utility and there are no borrowing or short-sales constraints on asset allocation.
} 
39 will exacerbate financial cyclical fluctuations. Adrian and Shin [2007] in particular claim that fixed solvency capital requirements may have devastating procyclical consequences on the dynamic investment strategies of the financial intermediaries. Changes in assets valuations show up immediately on balance sheets that force banks and insurance companies to sell more assets during downturns in order to restore their solvency ratios. Our suggestion is to recognize the existence of mean reversion in equity returns in the way we determine the Solvency Capital Requirement (SCR hereafter). This modification of the methodology is countercyclical. It should induce intermediaries to be more conservative in long expansionary phases, and to be more risk-taking in downturns.

So, this paper proposes a measure of the Value-at-Risk based on the vector autoregression estimates. It is in line with existing measures in that it derives from the empirical distribution of the expected $k$-period returns. Nevertheless, it has the advantage of not imposing any assumption regarding the law of distribution of the sample but relies on bootstrapped quantiles instead. Our contribution to this topic is twofold. First, we exploit the joint autoregressive dynamics of equities returns and financial market cycle so as to take into account the influence of the recent cycle conditions on the VaR measure. Second, we propose a cycle-dependent measure of the Solvency Capital Requirement which accounts for the illiquidity risk.

Our application to French data points to a significant influence of the financial market cycle in explaining stock returns: the financial market cycle indicator Granger-causes returns on equities. Consequently, the VaR is also affected by the financial cycle. This finding is of particular interest in the current European context. Nowadays, one of the most important questions debated within the so-called Solvency II project is the definition of the rules determining the SCR. So far, the main propositions put forward to calibrate this SCR in Europe rely on the VaR at the one-year horizon and do not take into account neither the state of the financial cycle nor the investors horizon.

The paper is organized as follows. Section 1 presents the econometric methodology. Section 2 describes the data used for the vector autoregressive model estimation presented in Section 3. In Section 4, French equities VaR are compared across investment 
horizons and phases of financial cycle. Section 6 concludes.

\section{Vector autoregression modelling of VaR}

\subsection{The vector autoregressive model}

So as to simplify the presentation, and without loss of generality, let us consider the following vector autoregression of order one ${ }^{2}$ :

$$
\mathrm{z}_{t}=\Phi_{0}+\Phi_{1} \mathrm{z}_{t-1}+\mathrm{v}_{t}
$$

where

$$
\mathrm{z}_{t}=\left[\begin{array}{l}
\mathrm{x}_{t} \\
\mathrm{~s}_{t}
\end{array}\right]
$$

is a $m \times 1$ vector with $\mathrm{x}_{t}$, the $n \times 1$ vector of $\log$ excess returns and $\mathrm{s}_{t}$ the $m-n-1 \times 1$ vector of variables which have been identified as financial markets cycle indicators. In equation (1), $\Phi_{0}$ is the $m \times 1$ vector of intercepts and $\Phi_{1}$ is the $m \times m$ matrix of slope coefficients. It is assumed that the roots of the characteristic polynomial $\Phi(z)=I_{m}-\Phi_{1} z$ lie strictly outside the unit circle in absolute value, a condition which rules out nonstationary or explosive behavior in $z_{t}$. Finally, $\mathrm{v}_{t}$ is the $m \times 1$ vector of innovations which is assumed to be i.i.d. distributed with mean zero and covariance matrix $\Sigma_{v}$.

A very parsimonious version of this autoregressive model will be retained for the evaluation of VaR from French data. Let $R_{0 t}$ denote the nominal short rate and $r_{0 t}=$ $\log \left(1+R_{0 t}\right)$ the $\log$ (or continuously compounded) return on this asset that is used as a benchmark to compute excess returns on equities. Then, with $r_{e t}$ the log stock return, let $x_{e t}=r_{e t}-r_{0 t}$ denote the corresponding log excess returns. Finally, let $m_{c t}$ denote the cyclical component of the log price index, to be defined later in the paper. In our empirical work, we will estimate a vector autoregression in which $\mathrm{z}_{t}=\left(x_{e t}, m_{c t}\right)^{\prime}$.

\footnotetext{
${ }^{2}$ The analysis can be easily extended to more than one lag.
} 


\subsection{From vector autoregression to Value-at-Risk}

Following Campbell and Viceira [2004], the one-period log returns are added over $k$ successive periods in order to get the cumulative $k$-period log returns. The one corresponding to the log excess return on equities is denoted $x_{e t}^{k} \equiv \mathrm{x}_{e, t+1}+\cdots+\mathrm{x}_{e, t+k}$. The vector autoregression is particularly well suited for forecasting purposes. By forward recursion of equation (1), it is possible to derive the expression of $\left(z_{t+1}+\cdots+z_{t+k}\right)$ :

$$
\begin{aligned}
\mathrm{z}_{t+1}+\cdots+\mathrm{z}_{t+k}= & {\left[k+(k-1) \Phi_{1}+(k-2) \Phi_{1}^{2}+\cdots+\Phi_{1}^{k-1}\right] \Phi_{0}+\left(\Phi_{1}^{k}+\Phi_{1}^{k-1}+\cdots+\Phi_{1}\right) \mathrm{z}_{t} } \\
& +\left(1+\Phi_{1}+\cdots+\Phi_{1}^{k-1}\right) \mathrm{v}_{t+1}+\left(1+\Phi_{1}+\cdots+\Phi_{1}^{k-2}\right) \mathrm{v}_{t+2}+\cdots \\
& +\left(1+\Phi_{1}\right) \mathrm{v}_{t+k-1}+\mathrm{v}_{t+k},
\end{aligned}
$$

or equivalently:

$$
\mathrm{z}_{t+1}+\cdots+\mathrm{z}_{t+k}=\left[\sum_{i=0}^{k-1}(k-i) \Phi_{1}^{i}\right] \Phi_{0}+\left[\sum_{j=1}^{k} \Phi_{1}^{j}\right] \mathrm{z}_{t}+\sum_{q=1}^{k}\left[\sum_{p=0}^{k-q} \Phi_{1}^{p} \mathrm{v}_{t+q}\right],
$$

where the first two terms on the RHS correspond to the $k$-period conditional mean, $E_{t}\left(\mathrm{z}_{t+1}+\cdots+\mathrm{z}_{t+k}\right)$. Finally, the cumulative $k$-period log excess return on equities derives from equation (2) as follows:

$$
x_{e t}^{k}=M_{r}\left(\mathrm{z}_{t+1}+\cdots+\mathrm{z}_{t+k}\right),
$$

where the selection matrix is defined by $M_{r}=\left[\mathbf{I}_{n \times n} \mathbf{0}_{n \times(m-n-1)}\right]$. Dividing both sides of equation (3) by $k$ gives the annualized log excess return.

The value-at-risk obtains straightforwardly from equation (2). The VaR is basically defined as a number such that there is a probability $p$ that a worse excess (log-)return occurs over the next $k$ periods. As such, the VaR is a quantile of this return distribution. The VaR of a long position (left tail of the distribution function) over the time horizon $k$ with probability $p$ may hence be defined from:

$$
p=\operatorname{Pr}\left[x_{e t}^{k} \leq \operatorname{VaR}\right]=F_{k}(\operatorname{VaR})
$$


where $F(\cdot)$ denotes the cumulative distribution function of $x_{e t}^{k}$. The quantile function is the inverse of the cumulative distribution function from which the VaR obtains:

$$
\operatorname{VaR}_{k}(p)=F_{k}^{-1}(p)
$$

Since $x_{e t}^{k}$ is the sum of log excess returns over $k$ periods, it is also the log of the product of the excess returns (not taken in log) over $k$ periods. Hence, the VaR of the corresponding capital requirement simply obtains as:

$$
\operatorname{VaR}_{k}^{c r}(p)=\exp \left(\operatorname{VaR}_{k}(p)\right)-1
$$

Since we are interested in the value-at-risk for various time horizons, it is desirable to keep an equivalent risk level over all the horizons, which means adjusting $p$ with $k$. For instance, the standard $1-p=99.5 \%$ level retained in VaR analysis translates into one chance out of 200 for an event to occur on a yearly basis. In order to maintain the same yearly probability, the corresponding probability for horizon $k$ must be adjusted accordingly, that is $1-p=(99.5 \%)^{k}$. All the computations below will retain this horizon-adjusted probability.

As can be seen from equation (5), such a VaR measure is directly affected by the distribution chosen for $F(\cdot)$. It is now well-known that the normal distribution is not suitable for most speculative assets, even at the quarterly or yearly frequency. Since there is no consensus regarding which alternative distribution to choose, we propose to retain a bootstrap approach relying on the empirical distribution. Basically, this approach consists in resampling $S$ times the residuals estimated from model (1) so as to re-built $S$ simulated sequences of $\frac{1}{k}\left(\mathrm{z}_{t+1}+\cdots+\mathrm{z}_{t+k}\right)$ using equation (2). The method will be discussed to greater extend below and will be applied to the French data described in the next section.

\section{The French assets return data}

The short term rate is the 3-month PIBOR rate, obtained from Datastream from 1970Q1 to 1998Q4. It is then continued using the 3-month EURIBOR rate from 1999Q1 to 
2008Q3. The end-of-quarter values from this monthly series are retained to get quarterly observations, and $r_{0 t}$ denotes the log return on this 3 -month rate.

French data for equities prices and returns come from Morgan Stanley Capital International (MSCI) database and are available since December 1969. More precisely, quarterly stock market data are based on the monthly MSCI National Price and Gross Return Indices in local currency. From these data, a quarterly stock total return series and a quarterly dividend series are obtained following the methodology described in Campbell $[1999]^{3}$. Note that we depart from Campbell's approach by not including the tax credits on dividends which are applicable to France. Indeed, MSCI calculates returns from the perspective of US investors, so it excludes from its indices these tax credits which are available only to local investors. Campbell chooses to add back the tax credits quite roughly, by applying the 1992 rate of $33.33 \%$ to all the sample. Nevertheless, this rate hasn't remained fixed over the sample considered here (1970Q1 - 2008Q3). On top of this, the way dividends are taxed has also changed during that period. We couldn't find exact tax rate data for our sample, and guess that on average, the French tax credits system has increased the nominal stock returns by around $40 \%$. Nevertheless, we choose to work with data excluding tax credits. The equities excess return, $x_{e t}$, is then obtained by substracting $r_{0 t}$ from the log return on French equities.

Finally, we have to find a proxy variable for the financial market cycle. From a practitioner's point of view, a variable such as a moving average of the log of the stock market price index would seem to be a good candidate because of its simplicity. Nevertheless, such kind of proxy variable has the serious drawback that a moving average is backward-looking by nature, and for this reason would always be late compared to the current cycle. For this reason, we have chosen to extract the trend component of the log stock market price index using the filter proposed in Hodrick and Prescott [1997]. This filter is the most used one in the business cycles literature since more than three decades. Of course, this filter is not perfect (see e.g. King and Rebelo [1993], Cogley

\footnotetext{
${ }^{3}$ See also Campbell's "Data Appendix for Asset Prices, Consumption and the Business Cycle", March 1998, downloadable from Campbell's homepage.
} 
and Nason [1995], Pederson [2001] and Mise, Kim and Newbold [2005]) but it has the desirable property to eliminate unit roots up to order four: the Hodrick-Prescott (HP hereafter) filtered cyclical component of a non stationary series is stationary. Furthermore, because the HP filter uses all the sample to extract the cyclical component, it is well in line with the current cycle contrary to such backward-oriented filtering methods as the moving average class of filters for instance. The last, but not least, reason which motivated our choice is that it is available in most, if not all econometrics softwares. Finally, $m_{c t}$ denotes the HP filtered cyclical component of the quarterly log stock market price index data described in the previous paragraph. Figure 4 in Appendix reports the log returns and stock market cycle data.

Table 1 reports sample means, standard deviations and Dickey-Fuller unit root tests of our data computed for the whole sample, i.e. 1970Q4-2008Q3. To annualize the raw quarterly data of log returns, the mean is multiplied by 400 while the standard deviation is multiplied by 200 since the latter increases with the square root of the time interval in serially uncorrelated data. Moreover, the mean of log returns is adjusted by adding one-half its variance so that it reflects mean gross return.

Table 1: Sample statistics

\begin{tabular}{ccccc}
\hline \hline & mean & standard deviation & ADF stat (lags) & p-value \\
& & & & \\
$x_{e}$ & 5.72 & 22.88 & $-11.61(0)$ & 0.000 \\
$m_{c}$ & 0.00 & 0.16 & $-4.36(0)$ & 0.000 \\
\hline \hline
\end{tabular}

Remind that the stock return here does not include tax credits. When adding back, say, a $40 \%$ tax credit rate, the stock excess return would reach more than $8 \%$ per year. Regarding the ADF unit root tests, the deterministic component includes at most a constant under the stationary alternative. The lag order of the ADF regression was selected as the smallest one succeeding in eliminating residuals autocorrelation up to order 8. Unsurprisingly, the unit root null is strongly rejected for the excess log returns 
on equities and the financial market cycle series.

\section{Empirical assessment of the influence of the finan- cial market cycle on excess equities log returns}

In the sequel, we will consider an autoregressive model for $\mathrm{z}_{t}=\left(x_{e t}, m_{c t}\right)$ in equation (1). The lag order of is set to three, so as to eliminate residuals serial correlation: the null of no residuals autocorrelation up to order 8 is not rejected at the $38 \%$ level according to Box-Pierce statistics. The estimated model writes as follows:

$$
z_{t}=\Phi_{0}+\Phi_{1} z_{t-1}+\Phi_{2} z_{t-2}+\Phi_{3} z_{t-3}+v_{t}
$$

Due to the stock market data and the lag order, our estimation sample is 1971Q32008Q3, i.e. 149 observations. The results are reported in Table 3, see Appendix. It is worth noticing that both $\mathrm{ARCH}$ and White LM tests do not reject the homoskedasticity null hypothesis. Moreover, we have tested the $\Phi_{s}$ ' coefficient stability using the SupLR test described in e.g. Bastien and Bec [2007] which tests the null of no structural change against the alternative of a change in potentially all $\Phi_{s}$ ' coefficients at an unknown date. The SupLR statistics is found to be 26.80 , and its bootstrapped p-value is $78.97 \%$. Hence, no structural change has been detected in our sample.

So as to check for the dynamic relationship between the market cycle and the excess equities returns, we performed Granger-causality tests using the Likelihood Ratio statistic. Table 2 reports the LR statistics and the corresponding p-values for the test that the three lags of the variables in columns are jointly zero in the equation of the variables in raw. This statistics is distributed as a Chi-squared with three degrees of freedom. As can be seen from this table, the log excess return does not Granger-cause the market cycle at the 5\%-level. By contrast, the nullity of $m_{c}$ 's coefficients in the equation of $x_{e}$ is strongly rejected with a LR statistics of 40.37 to compare to a $\chi^{2}(3)$. Accordingly, we conclude that our proxy variable of the financial market cycle Granger-causes the log excess returns on equities. This confirms the relevance of the joint modelling of these 
Table 2: Granger (non-)causality tests

\begin{tabular}{llc}
\hline \hline & \multicolumn{2}{l}{ Explanatory variables } \\
& $m_{c, t-i}$ & $x_{e, t-i}$ \\
& & \\
Equation & & \\
$x_{e, t}$ & 40.37 & 18.62 \\
p-value & $(0.00)$ & $(0.00)$ \\
& & \\
$m_{c, t}$ & 90.69 & 7.37 \\
p-value & $(0.00)$ & $(0.07)$ \\
\hline \hline
\end{tabular}

two variables.

This causal link is further confirmed by the impulse response function of the log excess return on equities to an innovation in the market cycle. In order to identify this innovation, we performed a Choleski decomposition of $\Sigma_{v}$ - the variance-covariance matrix of the vector autoregression estimated residuals — retaining the following ordering of the variables in the model: $\left(m_{c t}, x_{e t}\right)$. Denoting $\mathrm{v}_{t}=\left(v_{t}^{m}, v_{t}^{x}\right)^{\prime}$ the residuals of model (1) for such an ordering of the variables, we define the structural innovations in the market cycle and the returns $\varepsilon_{t}=\left(\varepsilon_{t}^{m}, \varepsilon_{t}^{x}\right)^{\prime}$, with $E\left(\varepsilon \varepsilon^{\prime}\right)=I$, by:

$$
\mathrm{v}_{t}=G \varepsilon_{t},
$$

where $G$ is the lower-triangular $2 \times 2$ matrix such that $G G^{\prime}=\Sigma_{v}$. This choice allows the market's cycle innovations to affect instantaneously the excess return, while the return innovations influence the market cycle after one period only. ${ }^{4}$ Figure 1 below reports this impulse response function of $x_{e}$ to a favorable unit shock in the market cycle innovation, together with two-standard deviation confidence interval computed from 10,000 drawings of the estimated residuals. As can be seen from Figure 1, the instantaneous response of the excess return is positive, but then becomes significantly negative for two years before progressively going back to zero. Of course, an adverse shock would generate

\footnotetext{
${ }^{4}$ The results obtained from the alternative identification scheme are qualitatively similar.
} 


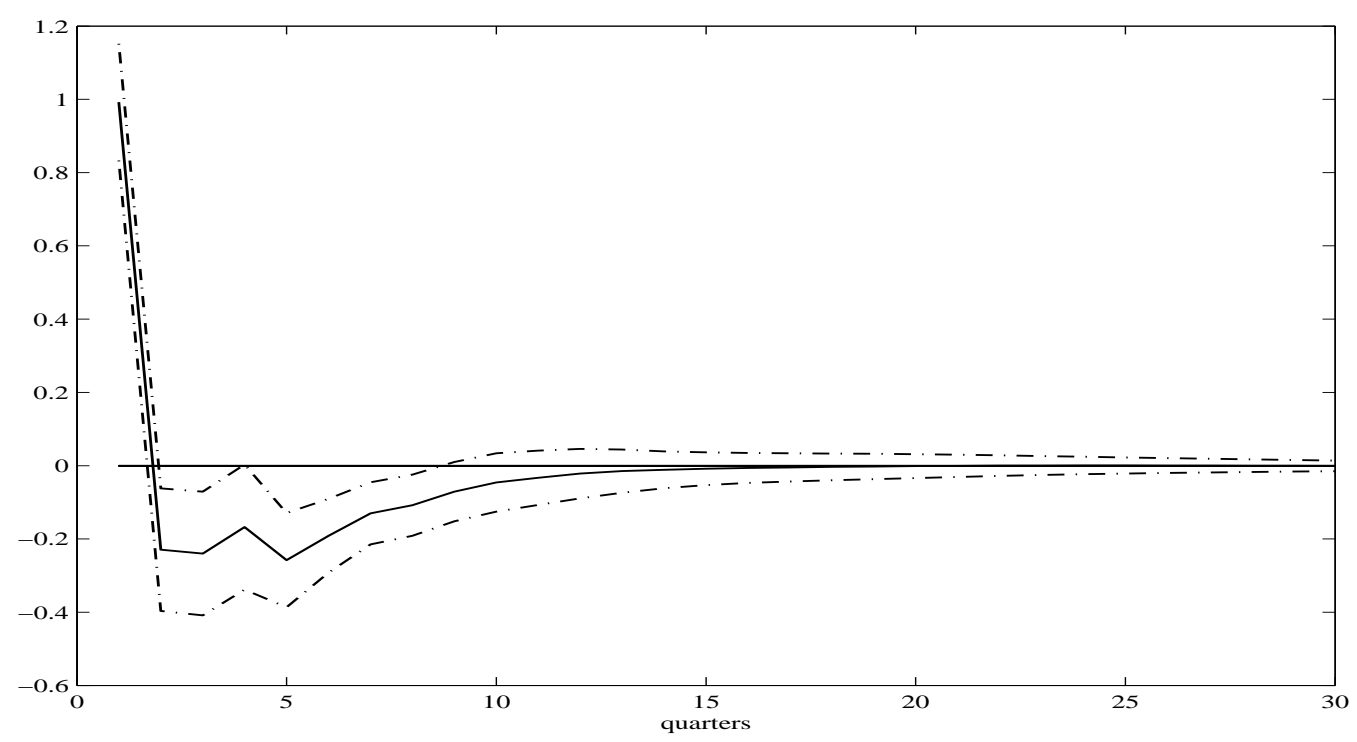

Figure 1: Response of $x_{e}$ to a unit shock in $\varepsilon^{m}$

the reverse effect: the log returns would drop the first quarter but then would become positive the next two years before the shock's effect completely vanishes. This figure also reveals that after eight quarters, the impact of the financial cycle innovation on the excess return is not significantly different from zero.

If the dynamics of the log returns is affected by innovations in market cycle, so should be the dynamics of the Value-at-Risk.

\section{The dynamics of Value-at-Risk}

\subsection{The proposed empirical measures of the $\mathrm{VaR}_{k}$}

The bootstrap method described below belongs to the multivariate filtered historical simulation (FHS) method presented in Chirstoffersen [2009]. This method consists in simulating future returns from a model using historical return innovations. It is qualified by "filtered" because it does not use simulations from the set of returns directly, but from the set of shocks, which are basically returns such as filtered by our vector autoregressive model. 
The FHS method described in Chirstoffersen [2009] would amount in our case to the following: First, using random draws from a uniform distribution, the estimated residuals of model (6) are resampled $S$ times. Using these $S$ series of $\mathrm{v}^{s}$ together with the estimated parameters of model (6) and the observed values of $\left\{\mathbf{z}_{i}\right\}_{i=t}^{t-2}$, in equation (3), $S$ hypothetical sequences of $x_{e t}^{k}$ are obtained. The $\operatorname{VaR}_{k}(p)$ then obtains by retaining - amongst these $S$ simulated sequences - the value of return such that there is a probability $p$ that a worse value occurs at horizon $k$. This method clearly accounts for the uncertainty of the shocks realization. However, by setting $\left\{\mathbf{z}_{i}^{s}\right\}_{i=t}^{t-2}=\left\{\mathbf{z}_{i}\right\}_{i=t}^{t-2}$, it makes the VaR measure strongly dependent on the last available observations. In order to illustrate this, Figure 2 reports this date-dependent VaR measure for investment horizons up to three years, for all $t$ from 1975Q1 to 2008Q3 together with the ex-post observed values of $\exp \left(x_{e t}^{k}\right)-1$. For all these investment horizons, the VaR is always below the observed ex-post values.

Nevertheless, since we aim at evaluating the impact of the financial cycle on the VaR for various investment horizons, we would rather control for the position in the cycle. We will do this by setting the excess return to its sample average, i.e. $\left\{\mathrm{x}_{\mathrm{e}}^{s}\right\}_{i=t}^{t-2}=\overline{\mathrm{x}_{\mathrm{e}}}$, while fixing the market cycle indicator respectively to its mean (mid-cycle measure), to its mean plus one-standard deviation (one-standard expansion case) and to its mean minus one standard deviation (one-standard recession case).

Another interesting measure of the $\mathrm{VaR}$ is one which would be made independent on the values retained for $\left\{z_{i}^{s}\right\}_{i=t}^{t-2}$. One way to achieve this is to use the $S$ bootstrapped series of $\mathbf{v}^{s}$ and the estimated parameters of model (6) to build $S$ hypothetical $\left\{\mathbf{z}_{i}^{s}\right\}_{i=1}^{T}$ and then set $\left\{\mathbf{z}_{i}^{s}\right\}_{i=t}^{t-2}=\left\{\mathbf{z}_{i}^{s}\right\}_{i=T}^{T-2}$. Hence, we will use $S$ different sets of values for $\left\{\mathbf{z}_{i}^{s}\right\}_{i=t}^{t-2}$ in order to compute the sequences of $x_{e t}^{k}$. By contrast with Chirstoffersen [2009]'s approach, this measure will incorporate the uncertainty on the values conditioning the forecasts. Consequently, we expect it to be more conservative than the other ones. Let us call it the a-cyclical measure. 

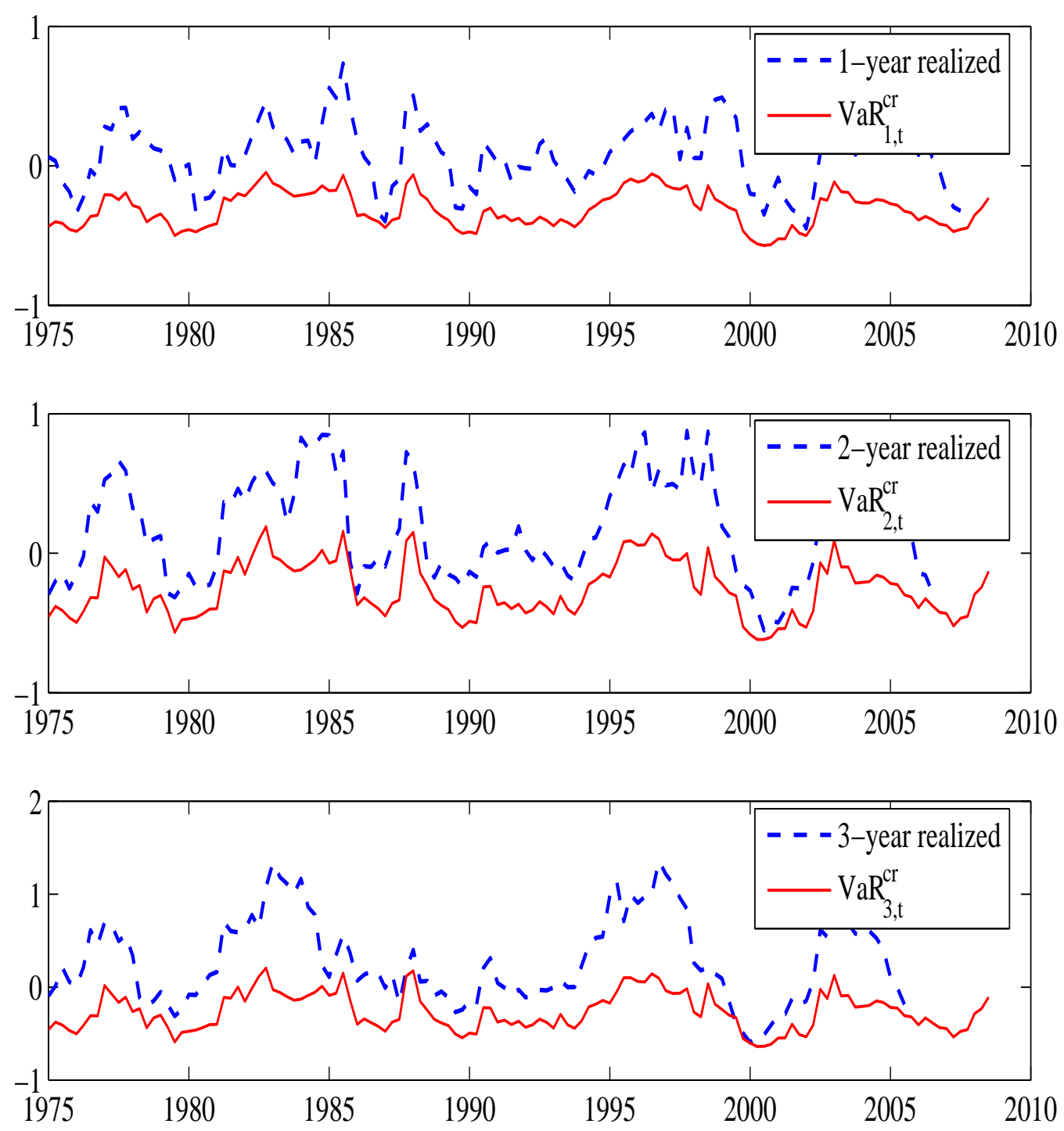

Figure 2: Value-at-Risk(99.5\%\%) across holding horizons 


\subsection{Empirical measures of $\mathrm{VaR}_{k}$ across investment horizon and financial cycle}

The results reported below were obtained for $S=300,000$ simulations for each $k=$ $1, \cdots, 20$ years, from which we picked up the corresponding $(1-99.5 k \%)$ quantile for each $V a R_{k}^{c r}$. Figure 3 plots the four measures of $V a R_{k}^{c r}$ described above, namely the mid-cycle, the one-standard expansion (denoted $+\sigma$ expansion), the one-standard recession (denoted $-\sigma$ recession), and the a-cyclical ones, against holding horizons up to twenty years ${ }^{5}$. The first important result emerging from this figure is that whatever

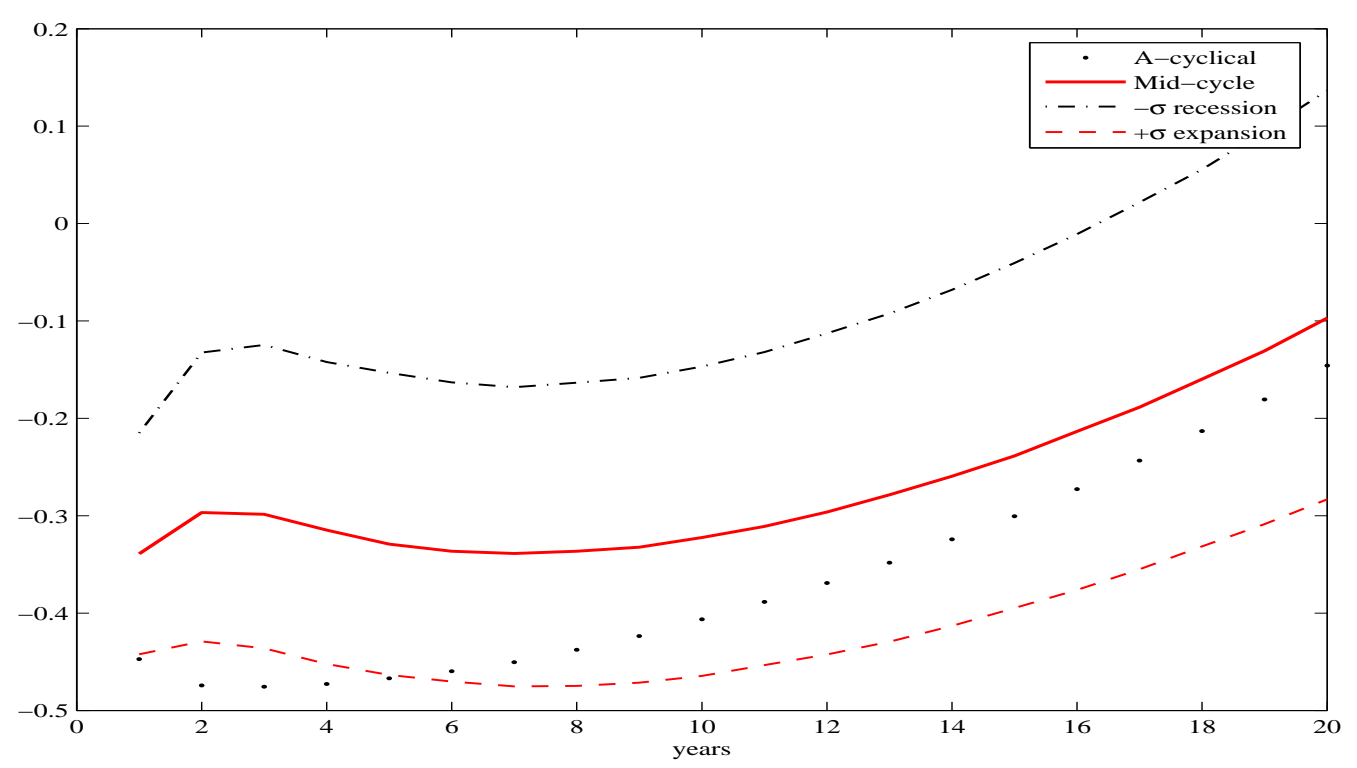

Figure 3: Value-at-Risk $\left(99.5^{k} \%\right)$ across holding horizons

the investment horizon, the VaR depends on the position in the financial cycle. When starting from a one-standard recession, the one-year VaR is around $-22 \%$ while it drops to $-44 \%$ when starting from a one-standard expansion. For all horizons, the VaR is stronger in expansion than in recession. This suggests that a rule imposing the same solvency capital requirement whatever the state of the financial market cycle could actually be pro-cyclical. It is worth noticing that our empirical value of the $V a R^{c r}$ at

\footnotetext{
${ }^{5}$ See the corresponding figures in Table 4 reported in the appendix.
} 
the one-year horizon starting from a mid-cycle position (-34\%) is very close to the ones reported in the 2007 Quantitative Impact Studies QIS3 of the Committee of European Insurance and Occupational Pensions Supervisors. Assuming a Gumbel distribution of returns, this study reports a $\operatorname{VaR} R^{c r}(99.5 \%)$ of $-36 \%$ using quarterly data of a European aggregate index from 1970 to $2006 .^{6}$

The second important result concerns the dynamics of the VaR across investment horizons. In a previous study (see Bec and Gollier [2007]), mean-reversion was found in $\log$ returns on French equities relatively to other assets returns: their relative risk was found decreasing with the holding period. This is confirmed by the results in Figure 3. Indeed, the worst expected loss in terms of capital requirement, at the (1$\left.0.995^{k}\right)$-percent level, decreases with the investment horizon. Starting from a standard recession, it could even become a gain after 17 years according to our estimates. These results are quite robust to the estimation period. The same exercise performed for different periods yields very close conclusions - see e.g. Figure 6 in appendix for the period from 1973Q3 to 2006Q3. As a further check, the simulations were also performed with re-estimation of the vector autoregression model for each $s \in S$ so as to take the parameters estimates uncertainty into account - which is not done in the common FHS approach. As a result, the cycle effect is quite robust to this additional source of uncertainty while the horizon effect is weaken (see Figure 5 in appendix).

Finally, due to the additional uncertainty it includes, the a-cyclical measure is always more conservative than the mid-cycle or the standard recession measures.

\section{Concluding remarks}

The vector autoregressive joint modelling of French equities excess returns and financial market cycle indicator reveals that the latter helps predicting the former. Put in other words, the financial market cycle variable Granger-causes the excess returns on equities.

\footnotetext{
${ }^{6}$ See the report "QIS3, Calibration of the underwriting risk, market risk and MCR", Committee of European Insurance and Occupational Pensions Supervisors, April 2007, p.36.
} 
Since the Value-at-Risk is evaluated from the expected excess returns, it is also influenced by the state of the financial cycle. If, starting from a mid-cycle position, the VaR at the one year horizon is found to be close to other existing measures (34\%), it can fall to $-44 \%$ when calculated from a one-standard expansion and even become a gain instead of a loss when calculated from a one-standard recession. Our results provide support to the claim that fixed solvency capital requirements may have important procyclical consequences on the dynamic investment strategies of the financial intermediaries. They also suggest some predictability in French equities returns since they point to a decrease in the VaR as the holding period increases. One limit of the approach retained here is that it is retrospective rather than prospective by nature. Indeed, the Hodrick-Prescott endpoints components estimates are in general inefficient since the filter is symmetric two-sided. Even though our main conclusions remain unchanged when excluding the first and last two years of the estimation sample ${ }^{7}$, research following the lines suggested by Mise et al. [2005] so as to overcome this issue in the definition of the financial cycle variable is ongoing. Extending this analysis to other European countries is also on our research agenda.

\section{References}

Adrian, T. and H.S. Shin, Liquidity and leverage, Working Paper, Federal Reserve Bank of New-York, New-York 2007.

_ de France, 2008, 11. February.

Barberis, N., Investing for the long run when returns are predictable, Journal of Finance, 2000, 55, 225-264.

\footnotetext{
${ }^{7}$ See Figures 6 and 7 in the appendix.
} 
Bastien, A. and F. Bec, The Transmission of Aggregate Supply and Aggregate Demand Shocks in Japan: Has There Been a Structural Change?, Studies in Nonlinear Dynamics and Econometrics, 2007, 11, No 4, art 5.

Bec, F. and C. Gollier, Assets Returns Volatility and Investment Horizon, Working paper 467, IDEI, University of Toulouse 12007.

Campbell, J., A variance decomposition for stock returns, Economic Journal, 1991, 101, $157-179$.

_ _ Understanding risk and return, Journal of Political Economy, 1996, 104, 298-345.

— Asset Prices, Consumption, and the Business Cycle, in J. Taylor and M. Woodford, editors, Handbook of Macroeconomics, vol.1, North-Holland: Amsterdam, 1999, pp. 1231-1303.

—_ and L. Viceira, Strategic Asset Allocation, Oxford University Press, 2002.

—_ and __ Long-Horizon Mean-Variance Analysis: A User Guide, Manuscript, Dept of Economics, Harvard University, Cambridge MA 2004.

_ , Y. Chan, and L. Viceira, A Multivariate Model of Strategic Asset Allocation, Journal of Financial Economics, 2003, 67, 41-80.

Chirstoffersen, P., Value-at-Risk models, in T. Andersen, R. Davis, J.-P. Kreiss, and T. Mikosch, editors, Handbook of Financial Time Series, vol.1, Springer Verlag, 2009. Forthcoming.

Cogley, T. and J.M. Nason, Effects of the Hodrick-Prescott filter on trend and difference stationary time series: Implications for business cycle research, Journal of Economic Dynamics and Control, 1995, 19, 253-278.

Hodrick, R. and E. Prescott, Postwar U.S. Business Cycles: An Empirical Investigation, Journal of Money, Credit and Banking, 1997, 29, 1-16. 
King, R. and S. Rebelo, Low frequency filtering and real business cycles, Journal of Economic Dynamics and Control, 1993, 17, 207-231.

Mise, E., T.-H. Kim, and P. Newbold, On suboptimality of the Hodrick-Prescott filter at time series endpoints, Journal of Macroeconomics, 2005, 27, 53-67.

Pederson, T.M., The Hodrick-Prescott Filter, the Slutzky Effect, and the Distortionary Effect of Filters, Journal of Economic Dynamics and Control, 2001, 8, 1081-1101.

Plantin, G., H. Sapra, and H.S. Shin, Marking-to-market: Panacea or Pandora's box?, Journal of Accounting Research, 2008, 46 .

Rochet, J.-C., Procyclicality of financial systems: Is there a need to modify current accounting and regulatory rules?, Financial Stability Review, Banque de France, 2008, 12. 


\section{Appendix}
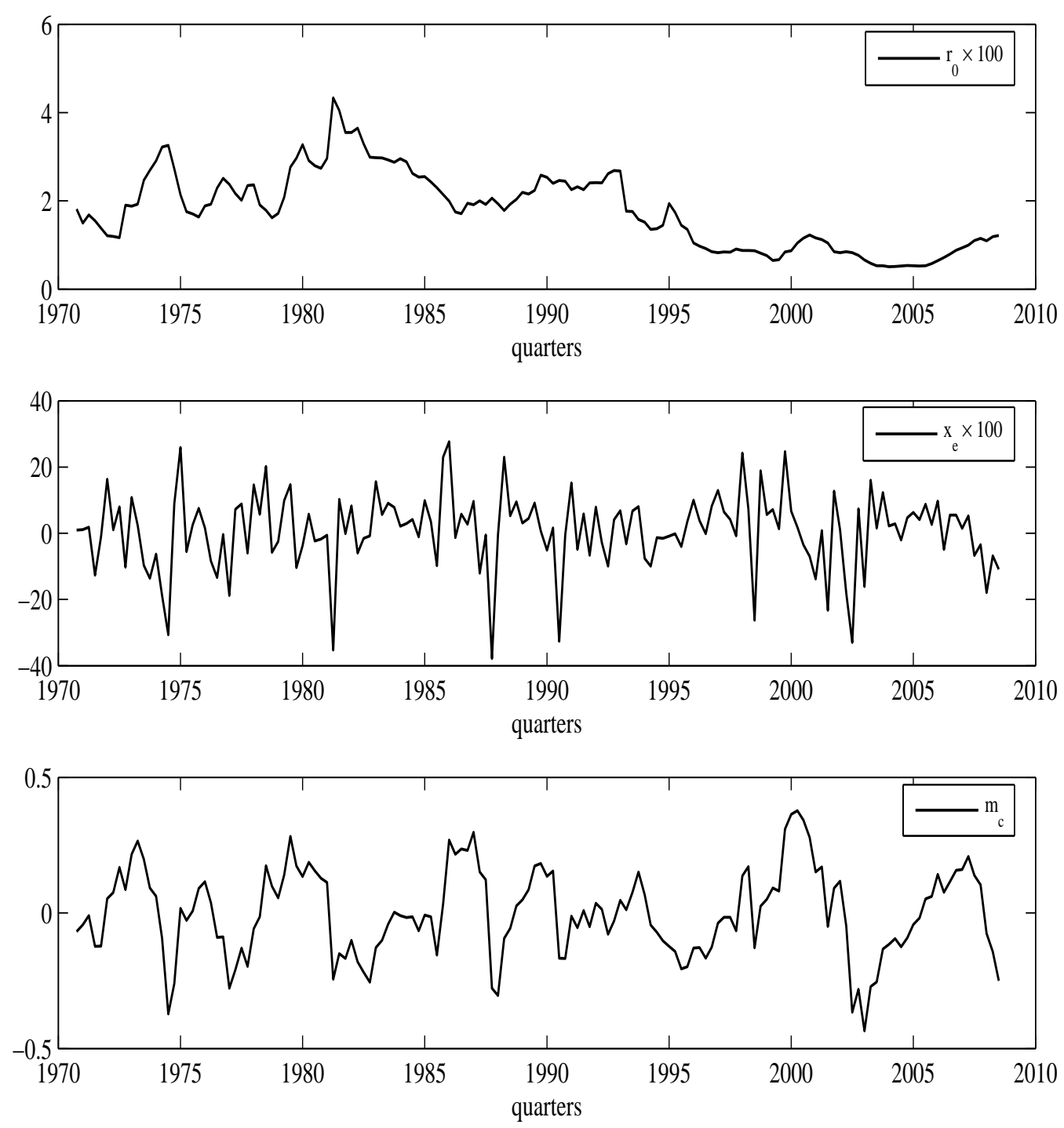

Figure 4: French data (1970Q4-2008Q4) 


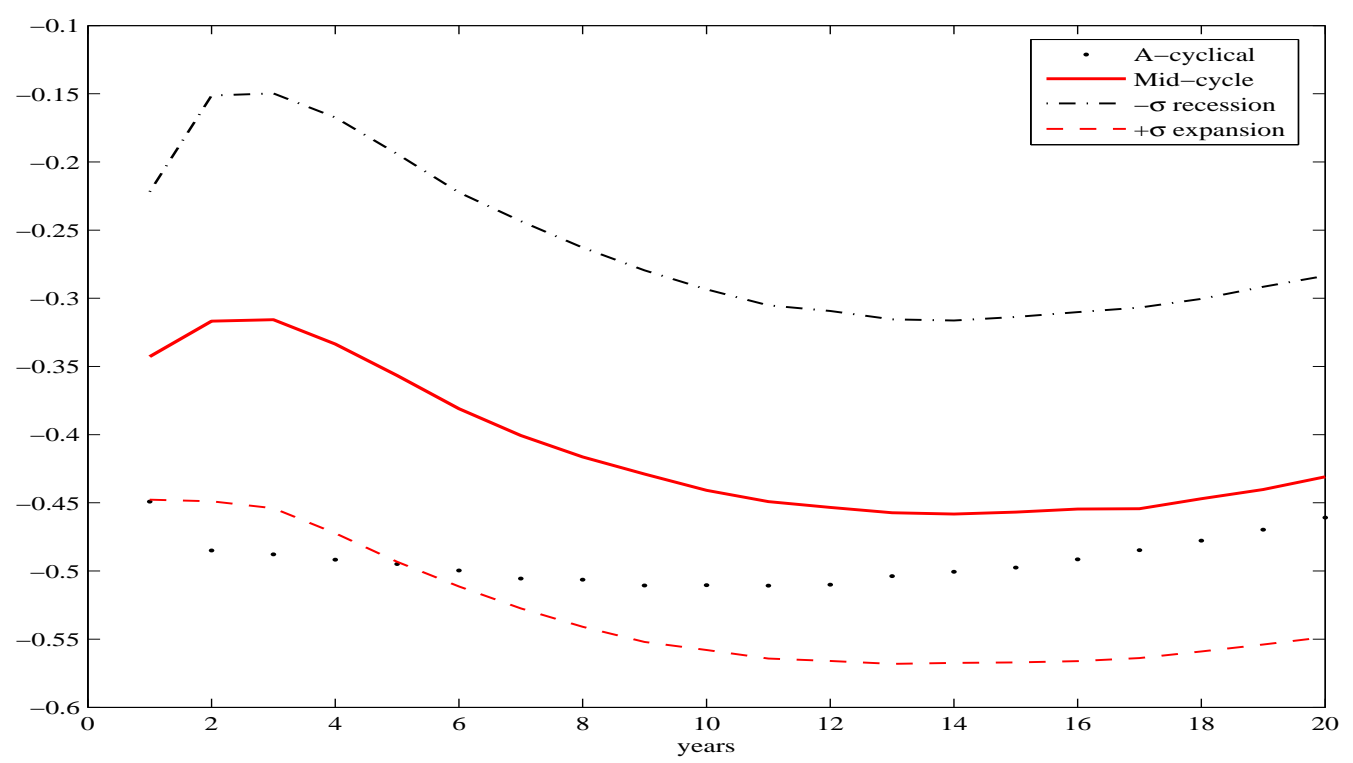

Figure 5: Value-at-Risk(99.5\%\%) when taking parameters uncertainty into account 


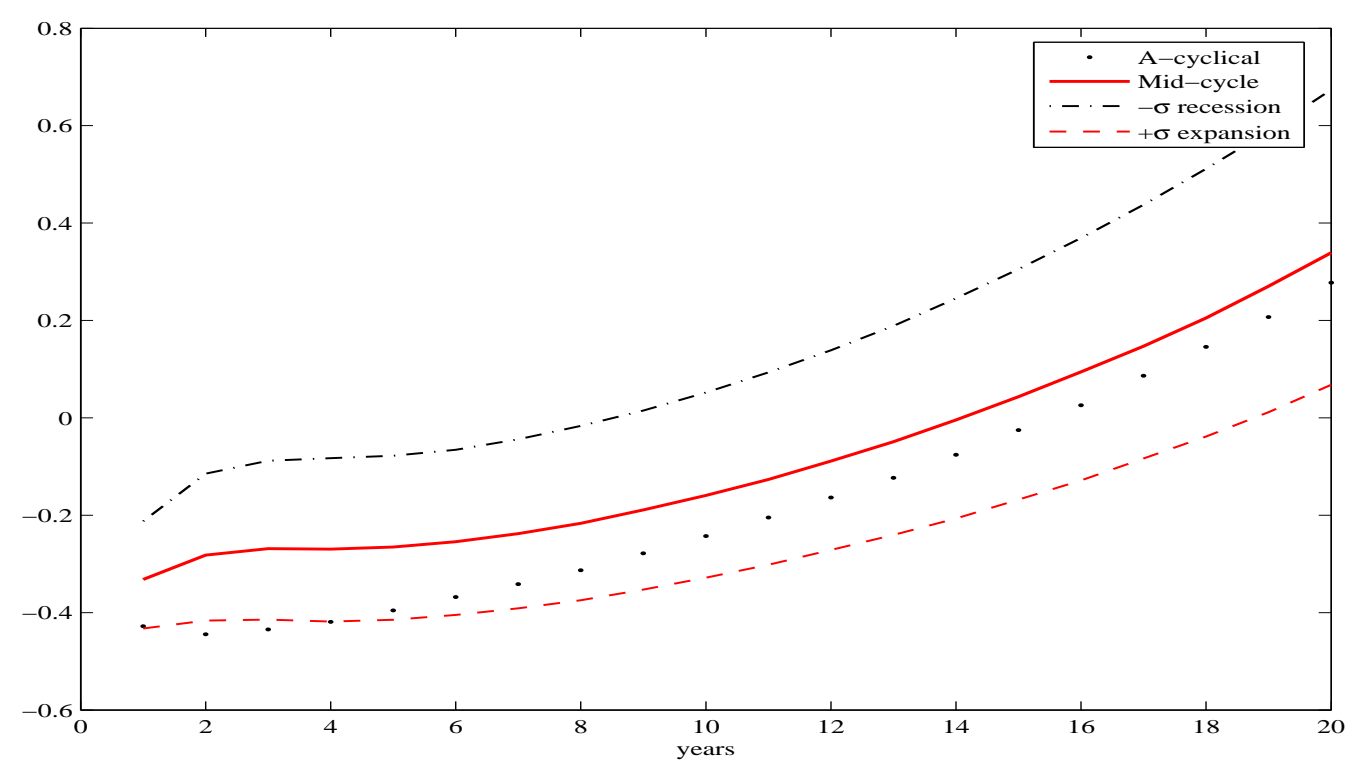

Figure 6: Value-at-Risk(99.5\%\%): first and last two years excluded

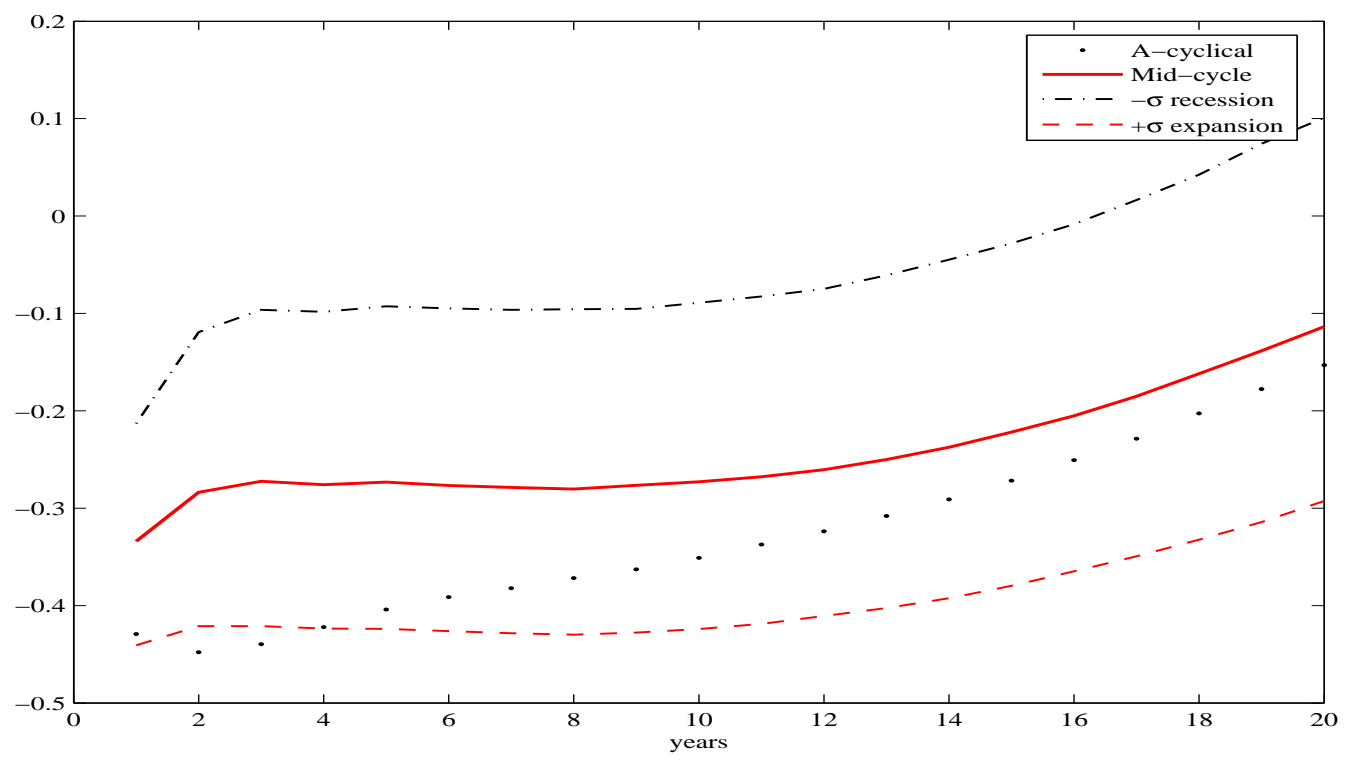

Figure 7: Value-at-Risk(99.5\% $)$ : first and last two years excluded and with parameters uncertainty 
Table 3: VAR estimation results

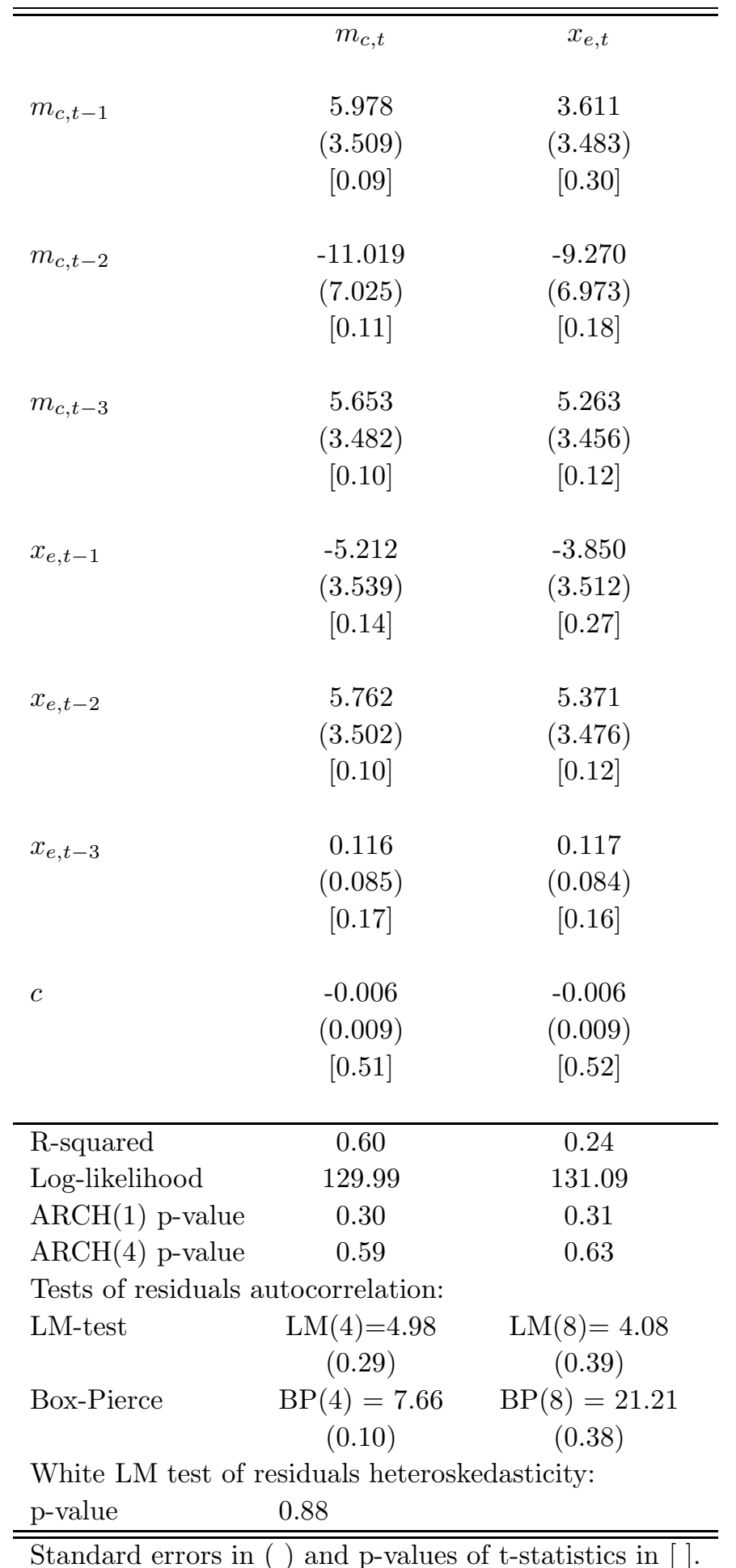


Table 4: $\operatorname{VaR}_{k}^{c r}\left(1-0.995^{k}\right)$ across investment horizon $k$

\begin{tabular}{lcccc}
\hline \hline & mid-cycle & $-\sigma$ recession & $+\sigma$ expansion & a-cyclical \\
Years & & & & \\
1 & -0.33919 & -0.21502 & -0.44230 & -0.44726 \\
2 & -0.29677 & -0.13250 & -0.42907 & -0.47431 \\
3 & -0.29859 & -0.12470 & -0.43608 & -0.47553 \\
4 & -0.31471 & -0.14225 & -0.45216 & -0.47277 \\
5 & -0.32926 & -0.15325 & -0.46341 & -0.46704 \\
6 & -0.33655 & -0.16303 & -0.47033 & -0.45975 \\
7 & -0.33877 & -0.16811 & -0.47516 & -0.45042 \\
8 & -0.33646 & -0.16345 & -0.47471 & -0.43763 \\
9 & -0.33227 & -0.15851 & -0.47145 & -0.42352 \\
10 & -0.32232 & -0.14681 & -0.46447 & -0.40643 \\
11 & -0.31103 & -0.13198 & -0.45337 & -0.38841 \\
12 & -0.29628 & -0.11269 & -0.44247 & -0.36917 \\
13 & -0.27853 & -0.09245 & -0.42934 & -0.34816 \\
14 & -0.25945 & -0.06796 & -0.41317 & -0.32423 \\
15 & -0.23853 & -0.04049 & -0.39481 & -0.30056 \\
16 & -0.21349 & -0.01082 & -0.37623 & -0.27275 \\
17 & -0.18864 & 0.02168 & -0.35502 & -0.24346 \\
18 & -0.15971 & 0.05559 & -0.33157 & -0.21313 \\
19 & -0.13072 & 0.09511 & -0.30862 & -0.18065 \\
20 & -0.09695 & 0.13670 & -0.28310 & -0.14587 \\
\hline \hline
\end{tabular}




\section{CESifo Working Paper Series}

for full list see www.cesifo-group.org/wp

(address: Poschingerstr. 5, 81679 Munich, Germany, office@cesifo.de)

2533 Erkki Koskela and Jan König, The Role of Profit Sharing in a Dual Labour Market with Flexible Outsourcing, January 2009

2534 Tomasz Michalak, Jacob Engwerda and Joseph Plasmans, Strategic Interactions between Fiscal and Monetary Authorities in a Multi-Country New-Keynesian Model of a Monetary Union, January 2009

2535 Michael Overesch and Johannes Rincke, What Drives Corporate Tax Rates Down? A Reassessment of Globalization, Tax Competition, and Dynamic Adjustment to Shocks, February 2009

2536 Xenia Matschke and Anja Schöttner, Antidumping as Strategic Trade Policy Under Asymmetric Information, February 2009

2537 John Whalley, Weimin Zhou and Xiaopeng An, Chinese Experience with Global 3G Standard-Setting, February 2009

2538 Claus Thustrup Kreiner and Nicolaj Verdelin, Optimal Provision of Public Goods: A Synthesis, February 2009

2539 Jerome L. Stein, Application of Stochastic Optimal Control to Financial Market Debt Crises, February 2009

2540 Lars P. Feld and Jost H. Heckemeyer, FDI and Taxation: A Meta-Study, February 2009

2541 Philipp C. Bauer and Regina T. Riphahn, Age at School Entry and Intergenerational Educational Mobility, February 2009

2542 Thomas Eichner and Rüdiger Pethig, Carbon Leakage, the Green Paradox and Perfect Future Markets, February 2009

2543 M. Hashem Pesaran, Andreas Pick and Allan Timmermann, Variable Selection and Inference for Multi-period Forecasting Problems, February 2009

2544 Mathias Hoffmann and Iryna Shcherbakova, Consumption Risk Sharing over the Business Cycle: the Role of Small Firms' Access to Credit Markets, February 2009

2545 John Beirne, Guglielmo Maria Caporale, Marianne Schulze-Ghattas and Nicola Spagnolo, Volatility Spillovers and Contagion from Mature to Emerging Stock Markets, February 2009

2546 Ali Bayar and Bram Smeets, Economic and Political Determinants of Budget Deficits in the European Union: A Dynamic Random Coefficient Approach, February 2009 
2547 Jan K. Brueckner and Anming Zhang, Airline Emission Charges: Effects on Airfares, Service Quality, and Aircraft Design, February 2009

2548 Dolores Messer and Stefan C. Wolter, Money Matters - Evidence from a Large-Scale Randomized Field Experiment with Vouchers for Adult Training, February 2009

2549 Johannes Rincke and Christian Traxler, Deterrence through Word of Mouth, February 2009

2550 Gabriella Legrenzi, Asymmetric and Non-Linear Adjustments in Local Fiscal Policy, February 2009

2551 Bruno S. Frey, David A. Savage and Benno Torgler, Surviving the Titanic Disaster: Economic, Natural and Social Determinants, February 2009

2552 Per Engström, Patrik Hesselius and Bertil Holmlund, Vacancy Referrals, Job Search, and the Duration of Unemployment: A Randomized Experiment, February 2009

2553 Giorgio Bellettini, Carlotta Berti Ceroni and Giovanni Prarolo, Political Persistence, Connections and Economic Growth, February 2009

2554 Steinar Holden and Fredrik Wulfsberg, Wage Rigidity, Institutions, and Inflation, February 2009

2555 Alexander Haupt and Tim Krieger, The Role of Mobility in Tax and Subsidy Competition, February 2009

2556 Harald Badinger and Peter Egger, Estimation of Higher-Order Spatial Autoregressive Panel Data Error Component Models, February 2009

2557 Christian Keuschnigg, Corporate Taxation and the Welfare State, February 2009

2558 Marcel Gérard, Hubert Jayet and Sonia Paty, Tax Interactions among Belgian Municipalities: Does Language Matter?, February 2009

2559 António Afonso and Christophe Rault, Budgetary and External Imbalances Relationship: A Panel Data Diagnostic, February 2009

2560 Stefan Krasa and Mattias Polborn, Political Competition between Differentiated Candidates, February 2009

2561 Carsten Hefeker, Taxation, Corruption and the Exchange Rate Regime, February 2009

2562 Jiahua Che and Gerald Willmann, The Economics of a Multilateral Investment Agreement, February 2009

2563 Scott Alan Carson, Demographic, Residential, and Socioeconomic Effects on the Distribution of $19^{\text {th }}$ Century US White Statures, February 2009 
2564 Philipp Harms, Oliver Lorz and Dieter Urban, Offshoring along the Production Chain, February 2009

2565 Patricia Apps, Ngo Van Long and Ray Rees, Optimal Piecewise Linear Income Taxation, February 2009

2566 John Whalley and Shunming Zhang, On the Arbitrariness of Consumption, February 2009

2567 Marie-Louise Leroux, Endogenous Differential Mortality, Non-Contractible Effort and Non Linear Taxation, March 2009

2568 Joanna Bęza-Bojanowska and Ronald MacDonald, The Behavioural Zloty/Euro Equilibrium Exchange Rate, March 2009

2569 Bart Cockx and Matteo Picchio, Are Short-Lived Jobs Stepping Stones to Long-Lasting Jobs?, March 2009

2570 David Card, Jochen Kluve and Andrea Weber, Active Labor Market Policy Evaluations: A Meta-analysis, March 2009

2571 Frederick van der Ploeg and Anthony J. Venables, Harnessing Windfall Revenues: Optimal Policies for Resource-Rich Developing Economies, March 2009

2572 Ondřej Schneider, Reforming Pensions in Europe: Economic Fundamentals and Political Factors, March 2009

2573 Jo Thori Lind, Karl Ove Moene and Fredrik Willumsen, Opium for the Masses? Conflict-Induced Narcotics Production in Afghanistan, March 2009

2574 Silvia Marchesi, Laura Sabani and Axel Dreher, Agency and Communication in IMF Conditional Lending: Theory and Empirical Evidence, March 2009

2575 Carlo Altavilla and Matteo Ciccarelli, The Effects of Monetary Policy on Unemployment Dynamics under Model Uncertainty - Evidence from the US and the Euro Area, March 2009

2576 Falko Fecht, Kjell G. Nyborg and Jörg Rocholl, The Price of Liquidity: Bank Characteristics and Market Conditions, March 2009

2577 Giorgio Bellettini and Filippo Taddei, Real Estate Prices and the Importance of Bequest Taxation, March 2009

2578 Annette Bergemann and Regina T. Riphahn, Female Labor Supply and Parental Leave Benefits - The Causal Effect of Paying Higher Transfers for a Shorter Period of Time, March 2009

2579 Thomas Eichner and Rüdiger Pethig, EU-Type Carbon Emissions Trade and the Distributional Impact of Overlapping Emissions Taxes, March 2009 
2580 Antonios Antypas, Guglielmo Maria Caporale, Nikolaos Kourogenis and Nikitas Pittis, Selectivity, Market Timing and the Morningstar Star-Rating System, March 2009

2581 António Afonso and Christophe Rault, Bootstrap Panel Granger-Causality between Government Budget and External Deficits for the EU, March 2009

2582 Bernd Süssmuth, Malte Heyne and Wolfgang Maennig, Induced Civic Pride and Integration, March 2009

2583 Martin Peitz and Markus Reisinger, Indirect Taxation in Vertical Oligopoly, March 2009

2584 Petra M. Geraats, Trends in Monetary Policy Transparency, March 2009

2585 Johannes Abeler, Armin Falk, Lorenz Götte and David Huffman, Reference Points and Effort Provision, March 2009

2586 Wolfram F. Richter, Taxing Education in Ramsey’s Tradition, March 2009

2587 Yin-Wong Cheung, Menzie D. Chinn and Eiji Fujii, China's Current Account and Exchange Rate, March 2009

2588 Alexander Haupt and Silke Uebelmesser, Voting on Labour-Market Integration and Education Policy when Citizens Differ in Mobility and Ability, March 2009

2589 Hans Jarle Kind, Marko Koethenbuerger and Guttorm Schjelderup, Should UtilityReducing Media Advertising be Taxed?, March 2009

2590 Alessandro Cigno, How to Avoid a Pension Crisis: A Question of Intelligent System Design, March 2009

2591 Helmut Lütkepohl and Fang $\mathrm{Xu}$, The Role of the Log Transformation in Forecasting Economic Variables, March 2009

2592 Rainald Borck, Hyun-Ju Koh and Michael Pflüger, Inefficient Lock-in and Subsidy Competition, March 2009

2593 Paolo M. Panteghini, On the Equivalence between Labor and Consumption Taxation, March 2009

2594 Bruno S. Frey, Economists in the PITS?, March 2009

2595 Natalie Chen and Dennis Novy, International Trade Integration: A Disaggregated Approach, March 2009

2596 Frédérique Bec and Christian Gollier, Term Structure and Cyclicity of Value-at-Risk: Consequences for the Solvency Capital Requirement, March 2009 